\title{
Segmented Holographic Spectrum Splitting Concentrator
}

\author{
Silvana Ayala P. ${ }^{\mathrm{a}}$, Shelby Vorndran ${ }^{\mathrm{b}}$, Yuechen Wu $\mathrm{u}^{\mathrm{a}}$, Benjamin Chrysler ${ }^{\mathrm{a}}$, Raymond K. Kostuk ${ }^{\mathrm{a}, \mathrm{b}}$ \\ ${ }^{a}$ The University of Arizona: Department of Electrical and Computer Engineering, 1230 E Speedway \\ Blvd, Tucson, AZ USA 85721; ${ }^{b}$ College of Optical Sciences, 1630 E. University Blvd., Tucson, AZ \\ USA 85721
}

\begin{abstract}
This paper presents a segmented parabolic concentrator employing holographic spectral filters that provide focusing and spectral bandwidth separation capability to the system. Strips of low band gap silicon photovoltaic (PV) cells are formed into a parabolic surface as shown by Holman et. al. [1]. The surface of the PV segments is covered with holographic elements formed in dichromated gelatin. The holographic elements are designed to transmit longer wavelengths to silicon cells, and to reflect short wavelength light towards a secondary collector where high-bandgap PV cells are mounted. The system can be optimized for different combinations of diffuse and direct solar illumination conditions for particular geographical locations by controlling the concentration ratio and filtering properties of the holographic elements. In addition, the reflectivity of the back contact of the silicon cells is used to increase the optical path length and light trapping. This potentially allows the use of thin film silicon for the low bandgap PV cell material. The optical design combines the focusing properties of the parabolic concentrator and the holographic element to control the concentration ratio and uniformity of the spectral distribution at the high bandgap cell location. The presentation concludes with a comparison of different spectrum splitting holographic filter materials for this application.
\end{abstract}

Keywords: Solar energy, Spectrum Splitting, concentrating photovoltaics

\section{INTRODUCTION}

According to the Shockley-Queisser limit, the efficiency of converting solar illumination to electricity for single junction photovoltaic (PV) cells and systems is limited to 33\% [2]. It is possible to increase the efficiency by using PV cells with different bandgap energies that cover the solar spectrum. Multi-junction (MJ) PV cells have efficiencies of 46\% [3], however cells of this type are expensive and would prohibit widespread use in modules as in current use with silicon PV cells. High efficiency MJ PV cells are typically used in conjunction with a low cost optical collector to reduce the amount of expensive cell material that is required.

Holman et. al. [1,4] introduced a novel hybrid concentrator that incorporates a low energy bandgap PV cell material (silicon) on the optical collector surface in combination with a spectral filter. The optical collector is in the form of a parabolic concentrator to focus direct illumination onto either a thermal or high bandgap PV cell receiver. This approach allows the direct component of solar illumination to be concentrated on MJ cells and thermal receivers and the low bandgap cell material on the collector to convert diffuse illumination components. They described both continuous and segmented parabolic optical surfaces. This design allows much greater energy yield than can be obtained with only using a direct or diffuse illumination separately. In their work they used $3 \mathrm{M}$ reflective films for the spectral filter. In this work lower cost dichromated gelatin holographic elements are considered for use as optical filters.

\section{SYSTEM DESIGN}

This paper describes the design for a segmented parabolic concentrator employing holographic spectral filters that can provide focusing and spectral bandwidth separation capability to the system. The holographic elements are formed in dichromated gelatin emulsions and are mounted onto strips of low bandgap silicon photovoltaic cells, which are then formed into an approximate parabolic trough concentrator (Figure 1). In addition, the reflectivity of the back contact of the silicon cells is used to increase the optical path length and light trapping in the silicon cells. This can potentially allow the use of thin film silicon for the low bandgap PV cell material.

Different design parameters will be optimized and combined to obtain the maximum optical and conversion efficiency as well as the highest energy yield under different operating conditions. The parameters include:

Next Generation Technologies for Solar Energy Conversion VII, edited by Oleg V. Sulima,

Gavin Conibeer, Proc. of SPIE Vol. 9937, 99370L · (c) 2016 SPIE

CCC code: $0277-786 \mathrm{X} / 16 / \$ 18 \cdot$ doi: $10.1117 / 12.2236699$

Proc. of SPIE Vol. 9937 99370L-1 
a) Number of mirror segments

b) Spectrum splitting filter materials

c) Extra-focusing power offered by the holograms

d) Solar cells of different bandgap energies.

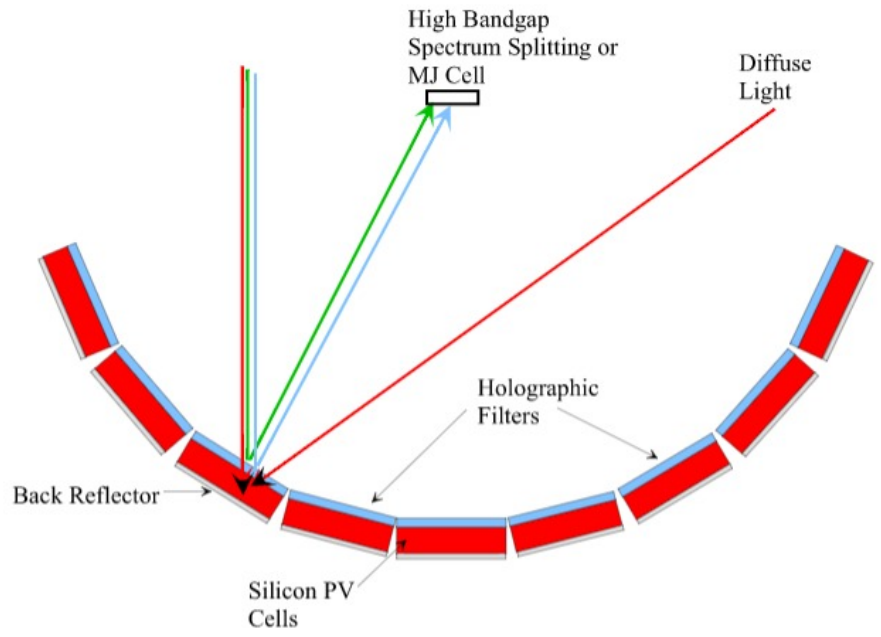

Figure 1 - Proposed segmented hybrid spectrum splitting concentrator with holographic optical elements.

The systems can be optimized for operation under different combinations of diffuse and direct solar illumination conditions that exist at a particular geographical location by controlling the concentration ratio and filtering properties of the holographic elements. For this purpose, configurations of the system with 6,10 and 14 segments are evaluated (Figure $2 \mathrm{~b}, \mathrm{~d}$ ). The focusing properties of the holographic element are considered, and compared to a system without the holographic element (Figure 2c).

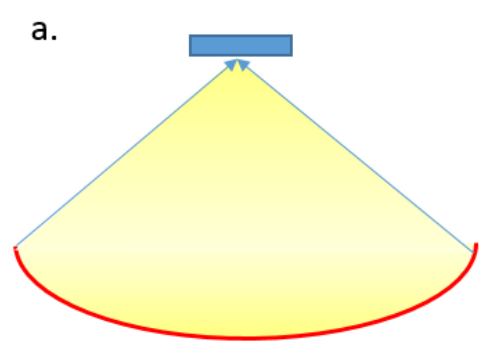

b.

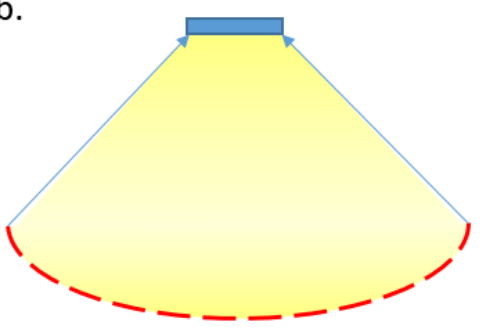

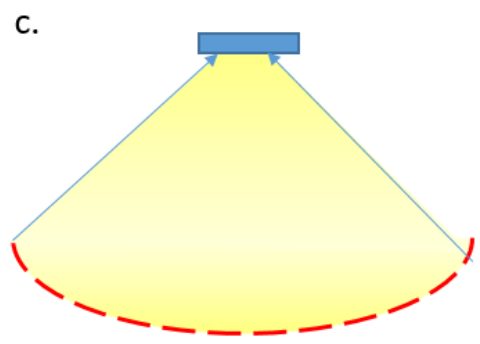

d.
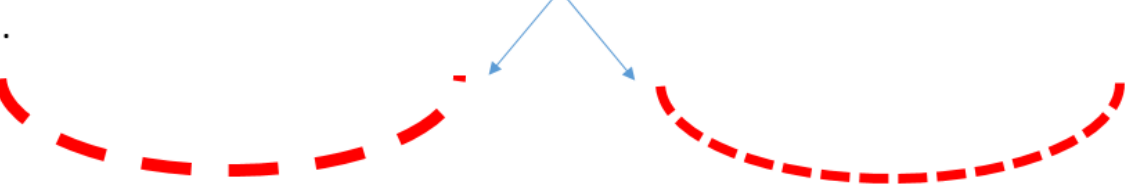

Figure 2 - different configurations analyzed in the paper. (a) Concentrator with a parabolic mirror focuses the light to one point. (b) System with 10 segments with planar reflection grating, focusing into a larger secondary area. (c) The focusing power of a holographic lens can help reduce the secondary area. (d) The system is also analyzed for 6 and 14 segments. 


\subsection{Spectrum Splitting System Geometry}

Parabolic reflectors have been used as concentrators in solar applications for several decades [5]. For a parabolic concentrator, incident rays that are parallel to the optical axis are reflected to the focal point (Figure 3a). Parabolic troughs are formed by establishing a parabolic shape in one plane (x-y) that focuses light along the z-axis [6]. In order to simplify manufacturing of a parabolic mirror, the main dish can be approximated with flat mirror segments. However, as a consequence the focal region is extended (Figure $3 \mathrm{~b}, \mathrm{c}$ ). For this application, the advantage of segmenting the parabolic concentrator is that it reduces fabrication and mounting costs associated with the silicon PV cells.
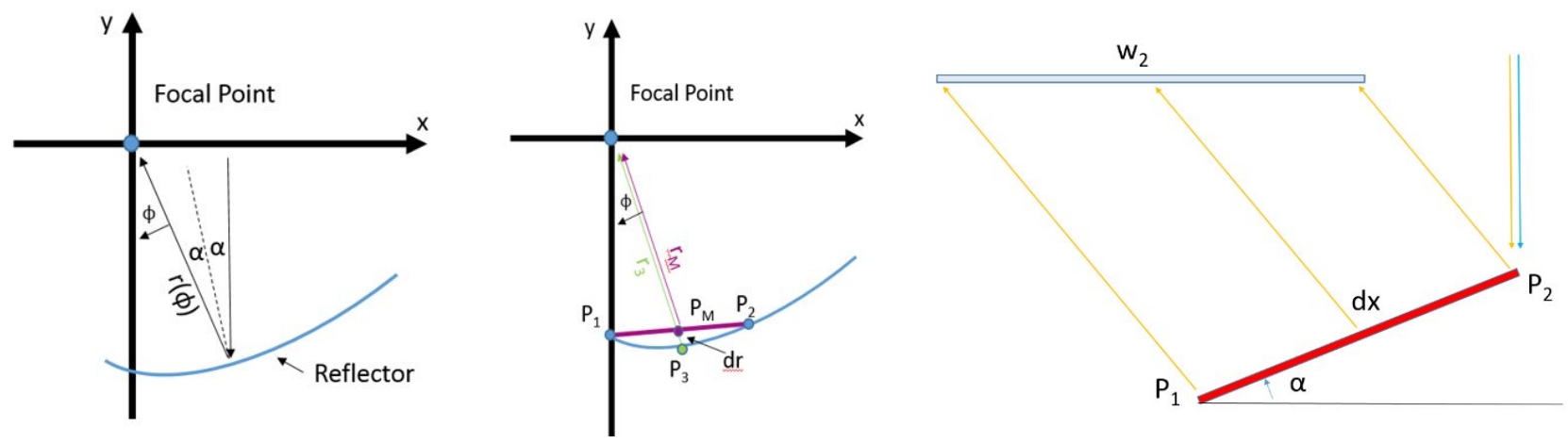

Figure 3 - (a) parameterizing a parabola. (b) deviation from the parabola by using flat segments. (c) Using a flat mirror instead of a parabolic reflector will change the focal point to a focal region $l_{2}$.

An approximate parabolic reflector can thus be formed by joining several segments of plane mirrors that have a width $d x$, that approximate a true parabolic shape. The path difference between the flat mirror approximation and the true parabola $(d r)$ will be more pronounced with fewer segments. Even though a perfect focus is not necessary, a smaller focal region is desirable to reduce the size of the more expensive MJ PV cell. Furthermore, this avoids losses due to shadowing from the receiver area. The width of the focal region $w_{2}$ will depend on the segment size $d x$, such that:

$$
w_{2}=\frac{d x}{\cos (\alpha)}
$$

where $\alpha$ is the angle made with the horizontal of the outermost segment as can be seen in Figure 3c. Larger mirror segments result in a larger beam width at the receiver and lower concentration but have the advantage of a simpler and easier to manufacture system configuration. Although there is no specific metric for an ideal segment size $(d x)$ the analysis that follows examines the effect of approximating the parabola with different numbers of segments.

\subsection{Spectrum Splitting PV Cell Selection and Performance Characteristics}

Single-junction solar cells rated under AM1.5 standard solar spectra have achieved efficiencies of up to $28.8 \%$, for GaAs, and $25 \%$ for silicon [7]. A useful metric for selecting PV cells for a spectrum splitting system is the spectral conversion efficiency (SCE) [8] given by:

$$
\operatorname{SCE}(\lambda)=V_{o c} F F S R(\lambda)
$$

where $\operatorname{SR}(\lambda)$ is the spectral responsivity, $\mathrm{V}_{\mathrm{oc}}$ is the open circuit voltage, and FF is the fill factor of a particular PV cell in the spectrum splitting system. An ideal spectrum splitting system consists of cells that have bandgap energies that span the incident solar spectrum, high fill factors, and different spectral responsivity characteristics. Table 1 shows the fill factor and $\mathrm{V}_{\mathrm{oc}}$ values for silicon and GaAs PV cells which will be evaluated for this system. 
Table 1 - Parameters used to convert from spectrum responsivity to spectrum conversion efficiency.

\begin{tabular}{|l|c|c|}
\hline & Silicon & GaAs \\
\hline FF (\%) & 82.7 & 86.5 \\
\hline Voc (V) & 0.740 & 1.122 \\
\hline Eff $(\%)$ & 25.6 & 28.8 \\
\hline
\end{tabular}

SCE specifies the optical to electrical conversion efficiency as a function of wavelength of a solar cell. The conversion efficiency of PV cell (i) in a spectrum splitting system can then be computed as:

$$
\eta_{p v_{i}}=\frac{1}{P_{A M 1.5}} \int T_{i}(\lambda) \cdot E_{A M 1.5}(\lambda) \cdot \operatorname{SCE}(\lambda)_{i} \cdot d \lambda
$$

where $T_{i}(\lambda)$ is the spectral transmittance of a filter in the spectrum splitting system; $P_{\text {AM1.5 }}$ is the integrated solar spectral irradiance, and $\mathrm{E}_{\mathrm{AM} 1.5}$ is the $\mathrm{AM} 1.5$ spectral irradiance.

\subsection{Optical Properties of the Spectrum Splitting System}

One approach to reduce the cost of the more expensive PV cell material is to collect solar illumination over a large area and to concentrate it onto a smaller PV cell area. The geometric concentration ratio for a 1D segmented parabolic concentrator is defined as:

$$
C R_{g}=\frac{\sum_{j=1}^{N} d x(j) \cos \alpha_{j}}{w_{2}}
$$

where $d x(j)$ are the widths of the primary collector with segments, $\alpha_{j}$ are the angles of the segments, $N$ is the number of segments, and $w_{2}$ is the width of the receiver at the focal plane. In a spectrum splitting system the concentration ratio is also a function of wavelength. The filter on the primary collector transmits longer wavelengths for conversion by the silicon PV cells and reflects shorter wavelengths to the high bandgap cell at the focal region.

Spectrum splitting filters can be evaluated by how well they approach ideal filter characteristics. An ideal filter should transmit $100 \%$ of a spectral component of the incident light to the PV cell that is most responsive to that spectral component as shown in Fig. 4a. The filtering properties of a holographic optical element can be controlled by its diffraction efficiency properties. The hologram parameters that can be modified are the thickness, refractive index modulation profile as a function of depth, and grating period. The composition, exposure, and processing parameters can be controlled to approximate an ideal filter function as shown Fig. $4 \mathrm{~b}$ for a reflection hologram formed in dichromated gelatin (DCG).
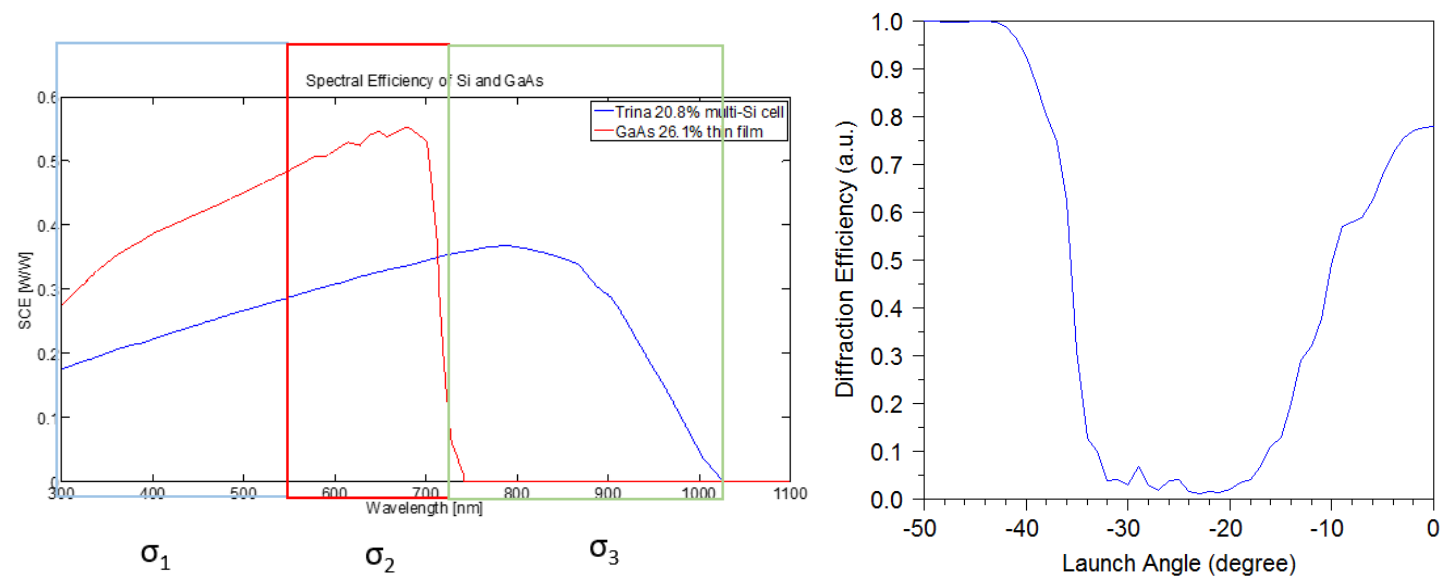

Figure 4- (a) An ideal spectrum splitting filter will transmit all the light in the selected bandwidth. (b) Diffraction efficiency for an experimental holographic filter for $750 \mathrm{~nm}$ as a function of angle. 


\section{SYSTEM MODEL AND RESULTS}

\subsection{System Model for the Segmented Parabolic Concentrator}

The performance of the segmented parabolic concentrator was evaluated using optical non-squential ray tracing software (FRED) [9], to determine the density of rays collected by the segmented parabolic surface and directed to the high bandgap PV cell surface. Three systems configurations are modeled as shown in Fig. 2: a) the segmented silicon surface without filters; b) the segmented silicon surfaces with holographic planar filters; and c) the segmented silicon surfaces with focusing holographic elements. The rays are weighted by the Fresnel reflection coefficients for the basic system (a) and also by the diffraction efficiency of the holographic elements (for systems (b) and (c)). The characteristics of holograms formed in dichromated gelatin are used for modeling the diffraction efficiency and spectral bandwidth of these elements. Direct and diffuse illumination conditions are evaluated by changing the 'source' distribution for rays that enter the system. The energy yield for different geographical locations was determined by integrating the power/area collected for a one-year time period using information from the Simple Model of the Atmospheric Radiative Transfer of Sunshine (SMARTS2) [10] simulation program.

The solar source model for direct normal incidence (DNI) conditions takes into account the finite size of the sun, by evaluating direct rays emitted between $+/-0.25^{\circ}$. Diffuse illumination is simulated, with rays entering the concentrator between $+/-90^{\circ}$. Different spectra were generated using the SMARTS2 simulation program for different geographical locations, at four intervals during the day and 4 days throughout the year (i.e. one day in mid-winter, spring, summer, and fall). The different systems configurations were evaluated for a locations ranging from high to low DNI conditions (Tucson, AZ, Tulsa, OK, Knoxville, TN, and Seattle, WA). Conditions were modeled using Typical Meteorological Year (TMY3) data [11].

Segmented parabolic concentrator performance with and without holographic filters are compared by evaluating the energy yield converted individually by the silicon and GaAs cells and by the combined energy yield from both cells. These values are also expressed as a percentage relative to the total available insolation at the different geographical locations.

The hologram diffraction efficiency was modeled using rigorous coupled wave analysis in the RSoft [12] simulation program for an arbitrary grating modulation profile. The arbitrary modulation profile is determined by comparing diffraction efficiency profiles between modeled and experimental hologram efficiency for dichromated gelatin holographic filters. The parameters used to model the holographic elements are given in Table 2. The optical efficiency of the concentrator was determined by tracing rays through the optical system that intercept the appropriate PV cell and weighting the rays by the diffraction efficiency at different wavelengths and angles of incidence.

Table 2 - Parameters used in the creation of the hologram and system.

\begin{tabular}{|l|l|}
\hline \multicolumn{1}{|c|}{ Parameter } & \multicolumn{1}{c|}{ Value } \\
\hline Holographic film thickness & $17 \mu \mathrm{m}$ \\
\hline Refractive Index Modulation & 0.08 \\
\hline System height & $1 \mathrm{~m}$ \\
\hline Number of segments & 6,10 and 14 \\
\hline Type of Hologram & $\begin{array}{c}\text { Reflective; planar and } \\
\text { focusing }\end{array}$ \\
\hline System width ( $\left.w_{l}\right)$ & $1.65 \mathrm{~m}$ \\
\hline Depth of primary collector area & $17 \mathrm{~cm}$ \\
\hline Aspect ratio (depth/width) & 0.606 \\
\hline $\begin{array}{l}\text { Collector surface width (low bandgap PV } \\
\text { cell) }\end{array}$ & $1.695 \mathrm{~m}$ \\
\hline High bandgap PV cell width (secondary) & $18.8 \mathrm{~cm}$ \\
\hline
\end{tabular}


It is assumed that the holographic element is encapsulated in glass, and the analysis accounts for Fresnel reflection coefficients. The optical properties for amorphous silicon are used with a $100 \%$ reflector on the back surface of the PV cell. Results for the cities of Tucson, Seattle and Knoxville are given in Table 3 through Table 5

Table 3 - System Energy Yield for Tucson, AZ

\begin{tabular}{|c|c|c|c|c|c|c|c|c|c|}
\hline & \multicolumn{2}{|c|}{ Insolation Received } & \multicolumn{3}{|c|}{$\begin{array}{c}\text { Spectrum Splitting System with } \\
\text { HOE }\end{array}$} & \multicolumn{3}{|c|}{ Non-HOE System } & \multirow[b]{2}{*}{$\begin{array}{l}\text { Improvement } \\
\text { with HOE }\end{array}$} \\
\hline \# of segments & $\begin{array}{l}\text { Total Direct } \\
\text { Insolation } \\
\text { (kWh) }\end{array}$ & $\begin{array}{c}\text { Total } \\
\text { Incident } \\
\text { Insolation } \\
\text { (kWh) }\end{array}$ & $\begin{array}{l}\text { Converted } \\
\text { Insolation: } \\
\text { Si (kWh) }\end{array}$ & $\begin{array}{c}\text { Converted } \\
\text { Insolation: } \\
\text { GaAs } \\
(\mathrm{kWh})\end{array}$ & $\begin{array}{c}\text { Insolation } \\
\text { Conversion } \\
\text { Efficiency }\end{array}$ & $\begin{array}{c}\text { Converted } \\
\text { Insolation: } \\
\text { Si (kWh) }\end{array}$ & $\begin{array}{c}\text { Converted } \\
\text { Insolation } \\
\text { GaAs } \\
(\mathbf{k W h})\end{array}$ & $\begin{array}{c}\text { Insolation } \\
\text { Conversion } \\
\text { Efficiency }\end{array}$ & \\
\hline 6 & \multirow{4}{*}{2546.8} & \multirow{4}{*}{3069.7} & 398.9 & 177.2 & 18.8 & 501.3 & 23.5 & 17.1 & 9.8 \\
\hline 10 & & & 564.8 & 194.6 & 24.7 & 713.0 & 23.6 & 23.6 & 3.1 \\
\hline 14 & & & 630.7 & 197.1 & 27 & 795.8 & 23.9 & 26.7 & 1 \\
\hline $\begin{array}{l}10 \text { Focusing } \\
\text { HOE Filter }\end{array}$ & & & 552.6 & 200.2 & 24.5 & 713.1 & 23.6 & 24 & 0.8 \\
\hline
\end{tabular}

Table 4 - System Energy Yield for Seattle, WA

\begin{tabular}{|c|c|c|c|c|c|c|c|c|c|}
\hline & \multicolumn{2}{|c|}{ Insolation Received } & \multicolumn{3}{|c|}{ Spectrum Splitting System with HOE } & \multicolumn{4}{|c|}{ Non-HOE System } \\
\hline \# of segments & $\begin{array}{c}\text { Total } \\
\text { Direct } \\
\text { Insolation } \\
(\mathbf{k W h )}\end{array}$ & $\begin{array}{c}\text { Total } \\
\text { Incident } \\
\text { Insolation } \\
\text { (kWh) }\end{array}$ & $\begin{array}{c}\text { Converted } \\
\text { Insolation: } \\
\text { Si (kWh) }\end{array}$ & $\begin{array}{c}\text { Converted } \\
\text { Insolation: } \\
\text { GaAs } \\
(\mathbf{k W h})\end{array}$ & $\begin{array}{c}\text { Insolation } \\
\text { Conversion } \\
\text { Efficiency }\end{array}$ & $\begin{array}{c}\text { Converted } \\
\text { Insolation: } \\
\text { Si (kWh) }\end{array}$ & $\begin{array}{c}\text { Converted } \\
\text { Insolation } \\
\text { GaAs } \\
(\mathbf{k W h})\end{array}$ & $\begin{array}{c}\text { Insolation } \\
\text { Conversion } \\
\text { Efficiency }\end{array}$ & $\begin{array}{c}\text { Improvement } \\
\text { with HOE }\end{array}$ \\
\hline 6 & \multirow{4}{*}{1158.3} & \multirow{4}{*}{1742.4} & 232.5 & 80.6 & 18 & 285.2 & 10.5 & 17 & 5.9 \\
\hline 10 & & & 327.2 & 87.2 & 23.8 & 403.3 & 10.5 & 23.7 & 0.1 \\
\hline 14 & & & 366.9 & 88.0 & 26.1 & 452.1 & 10.7 & 26.6 & -1.7 \\
\hline $\begin{array}{l}10 \text { Focusing } \\
\text { HOE Filter }\end{array}$ & & & 318.4 & 88.9 & 23.4 & 404.1 & 10.6 & 23.8 & -1.8 \\
\hline
\end{tabular}

Table 5 - System Energy Yield for Knoxville, TN

\begin{tabular}{|c|c|c|c|c|c|c|c|c|c|}
\hline & \multicolumn{2}{|c|}{ Insolation Received } & \multicolumn{3}{|c|}{ Spectrum Splitting System with HOE } & \multicolumn{3}{|c|}{ Non-HOE System } & \multirow[b]{2}{*}{$\begin{array}{c}\text { Improvement } \\
\text { with HOE }\end{array}$} \\
\hline \# of segments & $\begin{array}{c}\text { Total } \\
\text { Direct } \\
\text { Insolation } \\
(\mathbf{k W h})\end{array}$ & $\begin{array}{c}\text { Total } \\
\text { Incident } \\
\text { Insolation } \\
\text { (kWh) }\end{array}$ & $\begin{array}{l}\text { Converted } \\
\text { Insolation: } \\
\text { Si (kWh) }\end{array}$ & $\begin{array}{c}\text { Converted } \\
\text { Insolation: } \\
\text { GaAs } \\
(\text { kWh) }\end{array}$ & $\begin{array}{c}\text { Insolation } \\
\text { Conversion } \\
\text { Efficiency }\end{array}$ & $\begin{array}{c}\text { Converted } \\
\text { Insolation: } \\
\text { Si (kWh) }\end{array}$ & $\begin{array}{c}\text { Converted } \\
\text { Insolation } \\
\text { GaAs } \\
\text { (kWh) }\end{array}$ & $\begin{array}{c}\text { Insolation } \\
\text { Conversion } \\
\text { Efficiency }\end{array}$ & \\
\hline 6 & \multirow{4}{*}{1425.7} & \multirow{4}{*}{2124.9} & 283.5 & 100.4 & 18.1 & 348.6 & 13.1 & 17 & 6.1 \\
\hline 10 & & & 400.3 & 109.4 & 24 & 495.1 & 13.2 & 23.9 & 0.3 \\
\hline 14 & & & 449.1 & 110.0 & 26.3 & 554.5 & 13.3 & 26.7 & -1.5 \\
\hline $\begin{array}{l}10 \text { Focusing } \\
\text { HOE Filter }\end{array}$ & & & 389.1 & 111.8 & 23.6 & 495.6 & 13.2 & 23.9 & -1.6 \\
\hline
\end{tabular}


The results show that the insolation conversion efficiency improves as more segments are added both with and without the holographic elements. For regions with high DNI (Tucson) there is a slight improvement with holographic filters. However, the most significant improvement occurs when holographic filters are used in combination with the coarse approximation to a true parabolic concentrator. In particular, the use of six segments on Tucson increases the efficiency of the hoe-system by $24.4 \%$ over the non-HOE system. For cities with more direct to diffuse light ratio, there is also an improvement when using spectrum splitting although it is significantly lower as shown in Figure 5a. Figure 5b shows the normalized spectral irradiance and the GaAs receiver and indicates higher irradiance with a larger number of segments.
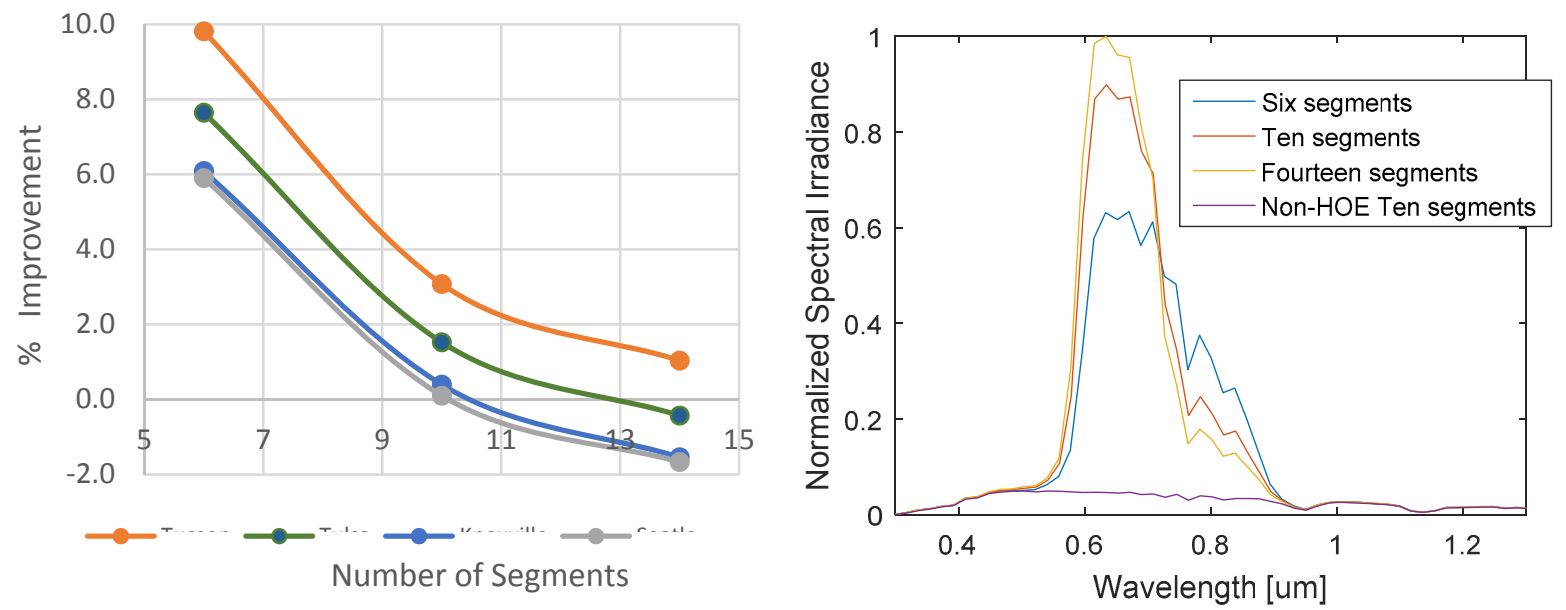

Figure 5 - (a) Energy yield for different cities, for the 6 segment configuration. (b) Normalized spectral irradiance on the secondary receiver, for Tucson location, with and without holographic element, normalized.

\section{CONCLUSIONS}

A segmented holographic spectrum splitting concentrator has been described and simulation results have been presented. The system proposed can be optimized for different combinations of diffuse and direct solar illumination conditions for particular geographical locations by controlling the concentration ratio and filtering properties of the holographic elements. The optical design combines the focusing properties of the parabolic concentrator and the holographic element to control the spectrum and power uniformity at the high bandgap cell location. The results show that a concentrator with few segments in combination with a holographic filter can provide significant improvement in insolation conversion over systems without holographic filters. This would allow traditional silicon cells to be used and reduced packaging complexity for a segmented PV cell parabolic concentrator.

\section{ACKNOWLEDGEMENTS}

The authors would like to thank the National Science Foundation (NSF) and Department of Energy (DOE) (EEC1041895, ECCS-1405619) for support of this work.

\section{REFERENCES}

[1] Yu, Zhengshan J., et al. "PV Mirror: a new concept for tandem solar cells and hybrid solar converters." Photovoltaics, IEEE Journal of 5.6 (2015): 1791-1799.

[2] W. Shockley and H. J. Queisser, "Detailed Balance Limit of Efficiency of p-n Junction Solar Cells," J. Appl. Phys., vol. 32, no. 3, p. 510, Mar. 1961.

[3] Kazmerski, Lawrence, D. Gwinner, and A. Hicks. "Best research-cell efficiencies." National Renewable Energy Laboratory (2010). 
[4] Yu, Zhengshan J., Kathryn C. Fisher, and Zachary C. Holman. "Evaluation of spectrum-splitting dichroic mirrors for PV mirror tandem solar cells. "Photovoltaic Specialist Conference (PVSC), 2015 IEEE 42nd. IEEE, 2015.

[5] W. A. Beckman, P. Schoffer, W. R. Hartman Jr, and G. O. G. Lof, "Design considerations for a 50-watt photovoltaic power system using concentrated solar energy," Sol. Energy 10(3), 132-136 (1966), doi:.

[6] Wheelwright, Brian. "Freeform Solar Concentrating Optics," Dissertation, University of Arizona, (2015)

[7] Green, Martin A., et al. "Solar cell efficiency tables (Version 45)." Progress in photovoltaics: research and applications 23.1 (2015): 1-9.

[8] Russo, J.M.; Vorndran, S.; Yuechen Wu; Kostuk, R., "Comparison of dispersive and non-dispersive spectrum splitting techniques for photovoltaic systems," Photovoltaic Specialist Conference (PVSC), 2014 IEEE 40th, vol., no., pp.2257,2261, 8-13 June 2014.

[9] "FRED Optimum software," Photon Engineering, Inc., http://www.photonengr.com/software/ (10 June 2015).

[10] "National Solar Radiation Data Base 1991-2005 update: typical metrological year 3," NREL, http://rredc.nrel.gov/solar/ old_data/nsrdb/1991-2005/tmy3/ (10 June 2015).

[11] C. A. Gueymard, "SMARTS2, A Simple Model of the Atmospheric Radiative Transfer of Sunshine: Algorithms and Performance Assessment," Florida Solar Energy Center FSEC-PF-270-95, 1-88 (1995).

[12] "DiffractMOD Product Overview," Synopsys, http://optics.synopsys.com/rsoft/rsoft-passive-device-diffract MOD.html (5 June 2015). 